\title{
Correlation between maternal mid upper arm circumference and neonatal anthropometry
}

\author{
Rani N. ${ }^{1}$, Phuljhele S. ${ }^{2}$, Beck P. ${ }^{3}$ \\ ${ }^{1}$ Dr Nimisha Rani, MD Student, ${ }^{2}$ Dr. Sharja Phuljhele, Professor and Head, ${ }^{3}$ Dr. Pratima Beck, Associate \\ Professor, all authors are attached with Department of Pediatrics, Pt. JNMMC and Dr BRAMH Raipur (C.G).
}

Address for Correspondence: Dr Nimisha Rani, Department of Pediatrics, Pt JNMMC, Raipur, E-mail: drnimisha99@gmail.com

\begin{abstract}
Introduction: An infant's birth weight has been identified as the best marker of optimal fetal growth and development. Maternal anthropometry (weight, height and Mid-Upper Arm Circumference) have been identified to influence an infant's birth weight and length. If MUAC can be established as a surrogate marker for neonatal anthropometric parameters it will help to plan the timely intervention for improvement of health of pregnant female. Aim: To study the correlation between maternal mid upper arm circumference and neonatal anthropometry. Material and Methods: A cross sectional study conducted in Dr. B R Ambedkar Memorial Hospital \& Pt. JNM Medical college Raipur, Chhattisgarh since January 2015 to September 2016. Sample size was 232. Materials like weighing machine, measuring tape, Infantometer, were used. Data was expressed as percentage and correlation was established using Spearman's chi square test $(\mathrm{p}<0.05)$. Data was analyzed using SSPS (version 16.0). Result: Significant correlation exists between maternal MUAC and birth Weight and length of neonates. Low birth weight is higher in female neonates. Birth length is higher in male neonates. MUAC of mother is a good predictor of risk of low birth weight as compared with other classic anthropometric measurements. Conclusion: Maternal MUAC is a significant predictor of neonatal anthropometry and can be used instead of pre- pregnancy weight to assess maternal nutritional status especially in resource poor setting.
\end{abstract}

Key words: Anthropometry, Infantometer, LBW, MUAC

\section{Introduction}

An infant's birth weight has been identified as the best marker of optimal fetal growth and development. Maternal anthropometry (weight, height and MUAC) have been identified to influence an infant's birth weight and length [1, 2]. Various studies have shown that Mid Upper Arm Circumference (MUAC) can be used as an indicator of the progress of pregnancy and its outcome [3-6].

Over 20 million infants worldwide are born with Low Birth Weight with more than $95.6 \%$ of these infants being born in developing countries [7]. SubSaharan Africa accounts for around 15\% of these LBWs where LBW is a strong determinant of infant mortality. South-Central Asia accounts for

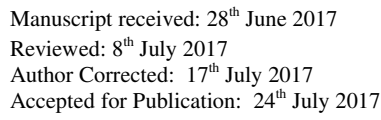

the largest percentage of all LBW infants worldwide where more than $27 \%$ of all infants weigh less than $2500 \mathrm{~g}$ [8]. Low birth weight and length are considered to be indicators not only of the health and nutrition status of pregnant women but also of the social development of a population.

A number of factors have been identified to be associated with LBW and length of infants in various studies but a baby's low weight at birth is dependent on two major factors: a premature birth or intrauterine growth retardation (IUGR).

The latter implies that the fetus growth has been inhibited and thus the fetus has not attained the potential growth. These two factors are in turn influenced by other factors as evidenced from a study conducted in Tehran, Iran in 15 university hospitals [9]. 
India, the most populous country in the South Asian region, contributes to the highest number of deaths among children under-five in the region (2.1 million deaths in 2006) and one-fifth of under-five deaths worldwide [8].

The government through the Ministry of Health has put in place interventions to ensure improved pregnancy outcomes such as introducing refocused ANC which recommends a minimum of four ANC visits by pregnant women.

MUAC has been found to have excellent correlations with weight, though its correlation with other anthropometric parameters remains to be explored in details.

Aim of the study: To study the correlation between maternal mid upper arm circumference and neonatal anthropometry.

\section{Materials and Methods}

This study is conducted in Dr. Bhimrao Ambedkar Memorial Hospital \& Pt. Jawaharlal Nehru Memorial Medical College Raipur, Chhattisgarh during year January 2015 to September 2016.

Study design- This was a cross sectional, observational, analytical study.

Study settings- Study was conducted in Dr. Bhimrao Ambedkar Memorial Hospital \& Pt. Jawaharlal Nehru Memorial Medical College, Raipur, Chhattisgarh after obtaining ethics committee approval.

Duration of study- Since January 2015 to September 2016.

Study size- Total 232 healthy mothers who received antenatal care and delivered at this hospital \& their healthy neonates are included in the study.

\section{Inclusion Criteria}

- For pregnant women- All the healthy pregnant women who received antenatal care with singleton pregnancy and free from any medical and surgical illness.

- For neonates- All the healthy term neonates, within $24 \mathrm{hr}$ of age without any congenital malformation.

\section{Exclusion criteria}

- For pregnant women- Any known medical or surgical illness, GDM, PIH, APH, Multiple pregnancies, alcoholics, smokers, sickle cell disease and HIV.

- For neonates- Any congenital malformation, preterm, Hydrops fetalis, birth injuries, cephalhematoma.

Participants- Subjects include pregnant women who attended antenatal care at Dr. Bhimrao Ambedkar Memorial Hospital, Raipur. These pregnant women were randomly selected.

The women who were sure of the date of their last menstrual period and willing to participate in the study after getting information about the study were recruited.

Two hundred thirty two women at different ages and trimester that met the inclusion criteria were used for the study.

Singleton term baby who was free from congenital malformation and clinically normal were included.

Variables- Weight, Length, mid upper arm circumference

\section{Statistical analysis}

- Data was expressed as percentage and mean \pm S.D.

- Kolmogorove- Smirnove analysis was performed for checking linearity of the data.

- Pearson correlation analysis was performed to check the correlation between two categorical variables.

- Fischer's exact test or Chi square test was used to analyze the significance of difference between frequency distribution of the data.

- $\mathrm{P}$ value $<0.05$ was considered as statistically significant.

- SPSS $\odot$ for windows ${ }^{\mathrm{TM}}$ Vs 17, IBM ${ }^{\mathrm{Tм}}$ Corp NY and Microsoft excel ${ }^{\mathrm{TM}}$ 2007, Microsoft ${ }^{\circledR}$ Inc USA was used perform the statistical analysis. 
Selection of cases- A self- administered structured pre-tested questionnaire was designed to cover background details, menstrual history, parity, past medical history, past obstetric history and the general health of the women. Two hundred thirty two women at different ages and trimester that met the inclusion criteria were used for the study.

Singleton term baby who was free from congenital malformation and clinically normal were included.

Mid upper arm circumference measured to the nearest millimeters using non-stretchable tapes at the midpoint between the acromion process and the

\section{Results}

Table 1: Mid upper arm circumference in study subjects:

\begin{tabular}{|c|c|c|}
\hline Mid upper arm circumference & Frequency & Percent \\
\hline$</=23$ & 150 & 28.9 \\
\hline $24-26$ & 67 & 6.5 \\
\hline $27-30$ & 15 & $\mathbf{1 0 0 . 0}$ \\
\hline Total & $\mathbf{2 3 2}$ & \\
\hline
\end{tabular}

Mid upper arm circumference was found to be $</=23 \mathrm{~cm}$ in 150 subjects $(64.7 \%), 24-26 \mathrm{~cm}$ in 67 (28.9\%) subjects and 27-30 cm in 15 (6.9\%) subjects. Mean MUAC was found to be $23 \mathrm{~cm}$.

Table 2: Gender of neonate

\begin{tabular}{|c|c|c|}
\hline Gender & Frequency & Percent \\
\hline Female & 131 & 56.5 \\
\hline Male & 101 & 43.5 \\
\hline Total & $\mathbf{2 3 2}$ & $\mathbf{1 0 0 . 0}$ \\
\hline
\end{tabular}

131 newborn were female $(56.5 \%)$ while $101(43.5 \%)$ were male.

Table 3: Birth weight of neonates.

\begin{tabular}{|c|c|c|}
\hline Birth weight & Frequency & Percent \\
\hline$<2.5$ & 121 & 52.2 \\
\hline$>/=2.5$ & 111 & 47.8 \\
\hline Total & $\mathbf{2 3 2}$ & $\mathbf{1 0 0 . 0}$ \\
\hline
\end{tabular}

Birth weight of neonates was found to be $<2.5$ in $121(52.2 \%)$ subjects while birth weight as found to be $>/=2.5$ $\mathrm{kg}$ in $111(47.8 \%)$ subjects. 
Table 4: Birth weight (Kg) of male and female neonates.

\begin{tabular}{|c|c|c|c|c|c|c|}
\hline & & & \multicolumn{2}{|c|}{ Gender of neonate } & \multirow[b]{2}{*}{ Total } & \multirow[t]{2}{*}{$P$ value } \\
\hline & & & Female & Male & & \\
\hline \multirow{4}{*}{$\begin{array}{c}\text { Birth weight } \\
(\mathrm{Kg})\end{array}$} & \multirow[t]{2}{*}{$<2.5$} & Count & 80 & 41 & 121 & \multirow[t]{4}{*}{0.002} \\
\hline & & $\begin{array}{c}\% \text { within Gender of } \\
\text { neonate }\end{array}$ & $61.1 \%$ & $40.6 \%$ & $52.2 \%$ & \\
\hline & \multirow[t]{2}{*}{$>/=2.5$} & Count & 51 & 60 & 111 & \\
\hline & & $\begin{array}{c}\% \text { within Gender of } \\
\text { neonate }\end{array}$ & $38.9 \%$ & $59.4 \%$ & $47.8 \%$ & \\
\hline \multirow{2}{*}{\multicolumn{2}{|c|}{ Total }} & Count & 131 & 101 & 232 & \\
\hline & & $\begin{array}{c}\% \text { within Gender of } \\
\text { neonate }\end{array}$ & $100.0 \%$ & $100.0 \%$ & $100.0 \%$ & \\
\hline
\end{tabular}

Birth weight $(\mathrm{Kg})$ of neonates in male and female neonates was compared using chi square test . Significant difference in distribution of two variables was noted. $(\mathrm{p}=0.002)$ indicating higher frequency of female neonates in low birth weight groups.

Table 5: Birth length $(\mathrm{cm})$ of male and female neonates.

\begin{tabular}{|c|c|c|c|c|c|c|}
\hline & & & \multicolumn{2}{|c|}{ Gender of neonate } & \multirow[t]{2}{*}{ Total } & \multirow[t]{2}{*}{$P$ value } \\
\hline & & & Female & Male & & \\
\hline \multirow[t]{6}{*}{ Birth length $(\mathrm{cm})$} & \multirow[t]{2}{*}{$</=40$} & Count & 14 & 6 & 20 & \multirow[t]{6}{*}{0.009} \\
\hline & & $\%$ within Gender of neonate & $10.7 \%$ & $5.9 \%$ & $8.6 \%$ & \\
\hline & \multirow[t]{2}{*}{$40.1-45$} & Count & 80 & 47 & 127 & \\
\hline & & $\%$ within Gender of neonate & $61.1 \%$ & $46.5 \%$ & $54.7 \%$ & \\
\hline & \multirow[t]{2}{*}{$>45$} & Count & 37 & 48 & 85 & \\
\hline & & $\%$ within Gender of neonate & $28.2 \%$ & $47.5 \%$ & $36.6 \%$ & \\
\hline \multirow{2}{*}{\multicolumn{2}{|c|}{ Total }} & Count & 131 & 101 & 232 & \\
\hline & & $\%$ within Gender of neonate & $100.0 \%$ & $100.0 \%$ & $100.0 \%$ & \\
\hline
\end{tabular}

Birth length of subjects was found to be $</=40 \mathrm{~cm}$ in $20(8.6 \%)$ subjects, while 127 subjects were having birth length (40.1-45 cm). Eighty five subjects had birth length $>45 \mathrm{~cm}(36.6 \%)$.

Birth length $(\mathrm{cm})$ of neonates in male and female neonates was compared using chi square test . Significant difference in distribution of two variables was noted. $(\mathrm{p}=0.009)$ indicating higher frequency of male neonates in $>45 \mathrm{~cm}$ birth length and higher frequency of female neonates in $</=40 \mathrm{~cm}$ birth length.

Table 6: Correlation of neonatal anthropometry with maternal MAUC.

\begin{tabular}{|c|c|c|}
\hline Neonatal Anthropometric parameter & Spearman's Rho & p Value \\
\hline Neonatal Weight $(\mathrm{Kg})$ & 0.65 & $<0.0001$ \\
\hline Neonatal length $(\mathrm{cm})$ & 0.47 & $<0.0001$ \\
\hline
\end{tabular}




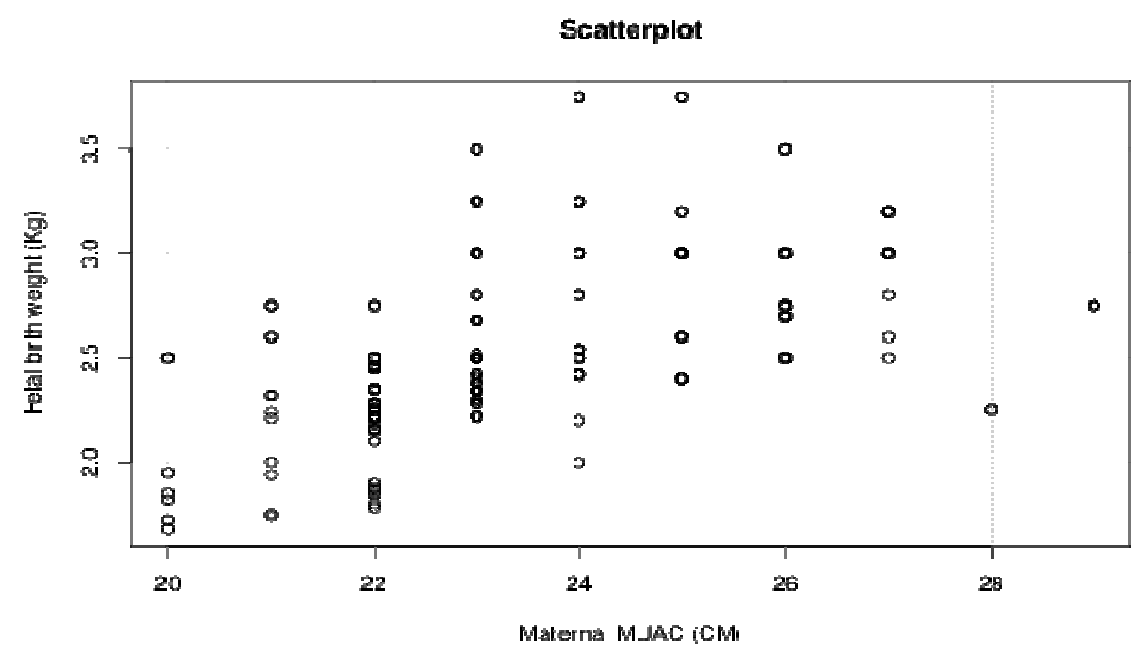

Correlation between maternal MUAC and Neonatal birth weight were found to be statistically significant $(\mathrm{p}<0.0001)$. Spearman rank correlation analysis was performed to assess the correlation of Neonatal birth weight with maternal MUAC. It was found that strong linear uphill correlation exists between maternal MUAC and neonatal birth weight (rho=0.65).

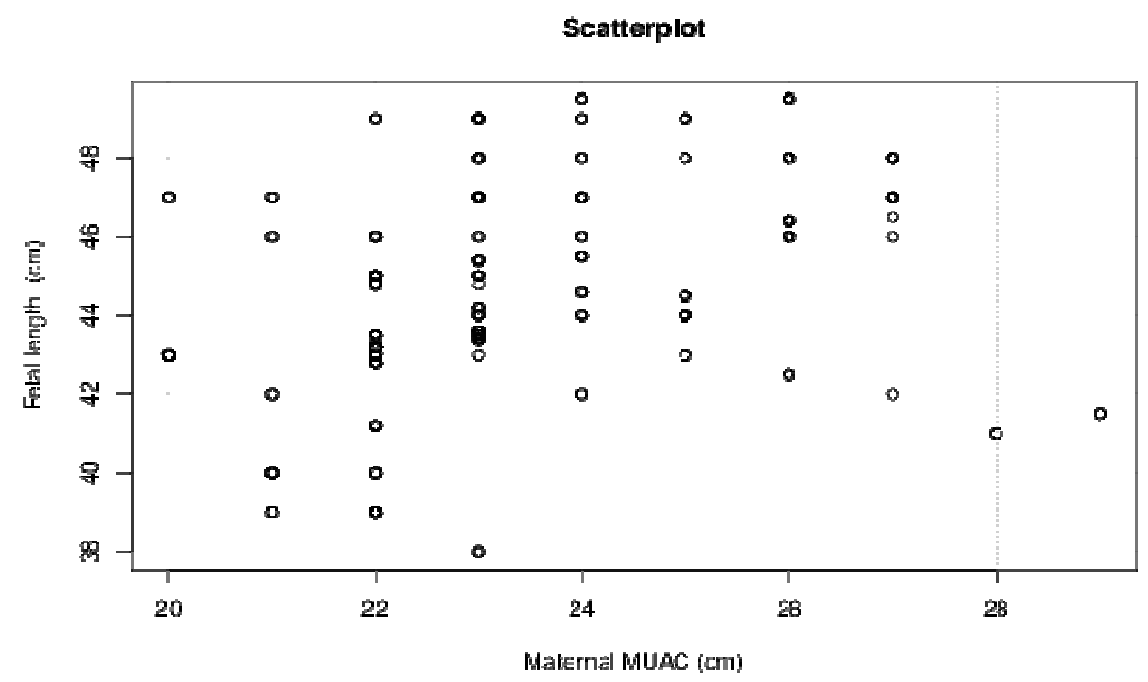

Correlation between maternal MUAC and Neonatal length were found to be statistically significant $(p<0.0001)$. Spearman rank correlation analysis was performed to assess the correlation of Neonatal birth length with maternal MUAC. It was found that moderate linear uphill correlation exists between maternal MUAC and neonatal length (rho $=0.47$ ).

\section{Discussion}

Various studies have shown that Mid Upper Arm Circumference (MUAC) can be used as an indicator of the progress of pregnancy and its outcome [3-6]. If MUAC can be established as a surrogate marker for neonatal anthropometric parameters it will help to plan the timely intervention for improvement of health of pregnant female. Unlike absolute weight or weight gain during pregnancy MUAC is fairly constant in mother throughout the pregnancy and hence if weights are not available, arm circumference taken at any time during pregnancy may serve as a useful proxy for prepregnancy weight [3]. Correlation of maternal MUAC and neonatal anthropometry will help us in strengthening adolescent health status as MUAC reflects pre pregnancy nutritional status. Maternal arm circumference can be used to assess the nutritional status of non-pregnant women and prior to or during pregnancy to identify women at risk of LBW and neonatal or infant mortality. 
Hence, arm circumference may be used to guide the amount of weight gain that is advisable for individual needs. Measurement of arm circumference can be very useful for rapid assessment of the nutritional status of women and can therefore, be incorporated into ongoing local and international surveys or surveillance systems if they can be proved to be useful.

If MUAC can be established as a surrogate marker for neonatal anthropometric parameters it will help to plan the timely intervention for improvement of health of pregnant female. We can achieve this target in the society by prompt early prenatal diagnosis of LBW infant and this can prove to be key step for designing targeted approach reducing anthropometric disadvantages in fetus eg. Low birth weight. MUAC has been found to have excellent correlations with weight, though its correlation with other anthropometric parameters remains to be explored in details [6].

Though many studies have assessed maternal MUAC in relation to the maternal weight, Neonatal weight and Neonatal mortality; very few studies have assessed the relation of MUAC with Neonatal anthropometric parameters such as Neonatal weight, crown rump length, and head circumference. Furthermore there is scarcity of such data in Indian population and specifically speaking Chhattisgarh population. Being a region with high incidence of LBW infants establishment of such correlation and designing surrogate marker for predicting Neonatal anthropometry will help to plan definitive and targeted health strategies. This will further help to reduce neonatal mortality

Study done by Mohanty et al [10] revealed that a MUAC measurement of $<22 \mathrm{~cm}$ in the first trimester was predictive of LBW. Consequently, maternal MUAC at delivery of $<22 \mathrm{~cm}$ is said to increase the relative risk of LBW. In our study MUAC of $23 \mathrm{~cm}$ has been taken as mean and it was seen that mother having MUAC $<23 \mathrm{~cm}$ having higher risk of low birth weight babies $(\mathrm{rho}=0.65)$ $(\mathrm{p}<0.0001)$.

Okereke et al [11] in their study found that there was no significant difference in the MUAC measurements across the 3 trimesters, which suggests that it is a measurement independent of gestational age.
Ververs et al [12] concluded that MUAC is the most reliable indicator of risk of $\mathrm{LBW}$ in a humanitarian context. They also concluded that measuring the mid upper arm circumference (MUAC) requires minimal equipment and has been found to predict morbidity and mortality as accurately as deficits in weight. As well, they suggested that a cut-off $<23 \mathrm{~cm}$ is a strong indicator for identifying a pregnant woman at high risk of LBW, and should also be a cut off to enroll women into a nutritional support programme. In our study, Mean MUAC was found to be $23 \mathrm{~cm}$.

One Study done in Guatemala, a cut-off level of $23.5 \mathrm{~cm}$ has shown high sensitivity (77\%) and specificity $(71 \%)$ for the prediction of low birth weight. Islam et al [13] performed study in Bangladesh and similar findings have been observed.

Khadivzadeh [6] looked at MUAC as indicator of nutritional status in women of reproductive age in Iran. They too found that BMI correlated strongly with MUAC. The cut-off of $24 \mathrm{~cm}$ was used to detect underweight females, it had a sensitivity of $93.6 \%$ and a specificity of $83.9 \%$.

Anamaría E. Ricalde et al[14] concluded that maternal mid-arm circumference (MUAC) was found to be positively correlated to birth weight $(\mathrm{r}=0.399)$. Similarly MUAC was significantly associated with crown-heel length $(r=0.306)$ and $(\mathrm{p}=0.0030)$, whereas in our study Neonatal birth weight $(\mathrm{rho}=0.65)$ and Neonatal length $(\mathrm{rho}=0.47)$ and $(\mathrm{p}<0.0001)$ similar to above study.

De onis $\mathrm{M}$ et al [15] proposed that there are many potential advantages to using the MUAC; accurate scales for weight and height measurements are not needed, and no calculation for BMI needs to be done. The other main advantage is that there is minimal change in MUAC during pregnancy. The MUAC would be much more useful in this setting of patients who book late and where there are resources constraints.

\section{Conclusion}

In our study, we recruited 232 healthy pregnant females. Mean MUAC was found to be $23 \mathrm{~cm}$. Low birth weight was higher in female neonates, Birth length was higher in male neonates. Significant correlation exists between maternal 
MUAC and birth Weight and length of neonates. Thus to conclude that-

MUAC is a good predictor of risk of low birth weight as compared with other classic anthropometric measurements. MUAC is closely related to maternal weight but is independent of gestational age, Therefore MUAC can be used instead of pre-pregnancy weight to assess maternal nutritional status.

The advantage of using MUAC to assess women at nutritional risk of giving birth to low birth weight babies is that arm circumference measurements can be taken whenever a woman visits a health worker or health center.

In pregnancy as nutritional assessment is problematic because serial weight monitoring is not feasible in developing countries and edema that develops particularly after the second trimester. So, MUAC can be used for nutritional assessment.

Since MUAC is a very simple technique, accurate scales as for weight and height measurements are not needed, and no calculation for BMI needs to be done. So, it can be used in resource poor setting and can be taken easily by health staff.

MUAC can be established as a surrogate marker for neonatal anthropometric parameters and it will help to plan the timely intervention for improvement of health of pregnant female Measurement of mid upper arm circumference can be very useful for rapid assessment of the nutritional status of women and can therefore be incorporated into ongoing local and international surveys or surveillance systems.

\section{Funding: Nil, Conflict of interest: None Permission of IRB: Yes}

\section{References}

1. Johnson AA, Knight ME, Edwards HC, Oyemade JU, Cole JO, Westney SL, Lovyea H, JonesS. Dietary Intakes, Anthro-pometric Measurements and Pregnancy Outcomes. Journal of Nutrition 1994, 86(2):1133-35.

2. Elshibly EM, Schmalisch G. Biomedical Centre of Public Health 8: 244 doi; 10.1186/1471-24888-24.
3. World Health Organization (WHO). Maternal Anthropometry And Pregnancy Outcomes, A WHO Collaborative Study. Bulletin of WHO OMS. 73s: 1-96.

4. Ricalde AE, Velásquez-Meléndez G, Tanaka AC, de Siqueira AA. Mid-upper arm circumference in pregnant women and its relation to birth weight. Rev Saude Publica. 1998 Apr;32(2):112-7.

5. Heiger ML, Luke B,Vande Ven C, Nugent C. Mid upper Arm Circumference (MUAC) Changes in Late Pregnancy Predict Fetal Growth in Twins. Twin Research and Human Genetics 2005. 8(3): 267-270.

6. Khadivzadeh T. Mid upper arm and calf circumferences as indicators of nutritional status in women of reproductive age. Eastern Mediterranean health Journal 2002; 8(4/5): 612-18

7. International Institute for Population Sciences (IIPS) (2007) National Family Health Survey (NFHS-3), 2005-06: India. Mumbai: IIPS

8. United Nations Children's Fund(UNICEF) (2008) The state of the world's children 2008: Child survival. New York: UNICEF, Available: http://www. unicef.org/ sowc08/ docs/sowc08.pdf. Accessed Aug2016.

9. Vahdaninia M, Tavafian SS, Montazeri A. Correlates of low birth weight in term pregnancies: a retrospective study from Iran. BMC Pregnancy Childbirth. 2008 Apr 19;8:12. doi: 10.1186/14712393-8-12.

10. Mohanty C, Prasad R, Srikanth Reddy A, Ghosh JK, Singh TB, Das BK. Maternal anthropometry as predictors of low birth weight. J Trop Pediatr. 2006 Feb;52(1):24-9. Epub 2005 Jun 24

11. Okereke CE, Anyaehie UB, Dim CC, Iyare EE, Nwagha UI. Evaluation of some anthropometric indices for the diagnosis of obesity in pregnancy in Nigeria: a cross-sectional study. Afr Health Sci. 2013 Dec; 13 (4):1034-40. doi: 10.4314/ahs. v13i4.25.

12. Ververs M, Antierens A, Sackl A, Staderini N, Captier V. Which anthropometric indicators 
identify a pregnant woman as acutely malnourished and predict adverse birth outcomes in a humanitarian context? PLOS curr. 2013 June; 5: PMC 3682760.

13. Islam MM, Kamruzaman M, Elahi MT, Ashrafuzzaman M, Azhar BS. Association of maternal body mass index (BMI) and mid upper arm circumference (MUAC) and birth weight of newborn in the southwest region of Bangladesh. Int J Food Nutri Sci 2104; 3(1):1-4.
14. Ricalde AE, Velásquez-Meléndez G, Tanaka AC, de Siqueira AA. Mid-upper arm circumference in pregnant women and its relation to birth weight. Rev Saude Publica. 1998 Apr; 32(2): 112-7.

15. de Onis M, Yip R, Mei Z. The development of MUAC-for-age reference data recommended by a WHO Expert Committee.Bull World Health Organ. 1997;75(1):11-8.

\section{How to cite this article?}

Rani N, Phuljhele S, Beck P. Correlation between maternal mid upper arm circumference and neonatal anthropometry. Int J Med Res Rev 2017;5(07):717-724.doi:10.17511/ijmrr. 2017.i07.10. 